\title{
EL TURISMO MARINERO COMO OPCIÓN DE DESARROLLO LOCAL SOSTENIBLE A PARTIR DEL EMPODERAMIENTO FEMENINO
}

\author{
Iria Caamaño Franco* \\ Universidade da Coruña \\ https://orcid.org/0000-0001-7983-8620 \\ María Andrade Suárez** \\ Universidade da Coruña \\ https://orcid.org/0000-0002-5957-1751 \\ Antonia Pérez-García*** \\ Universidade da Coruña \\ https://orcid.org/0000-0002-4655-8830
}

\section{RESUMEN}

El turismo marinero se ha convertido en un referente turístico con más de dos décadas de expansión a nivel internacional y en continuo crecimiento. En este contexto, el presente trabajo tiene como objetivo estudiar el turismo marinero como opción de desarrollo local sostenible a través del empoderamiento femenino. El estudio se ha basado en entrevistas semiestructuradas a mujeres que lideran proyectos de turismo marinero en Galicia y en un análisis de contenido de las noticias sobre el tratamiento que la prensa les otorga. Los resultados evidencian que la mayor parte de los proyectos tienen un carácter innovador, diversificado, participativo y responsable. Se constata que, a pesar del evidente avance, es necesario promover más la iniciativa empresarial femenina en el ámbito del turismo marinero, además de fomentar su presencia y proyección social a través de los medios.

Palabras clave: turismo marinero; emprendimiento femenino; sector pesquero; desarrollo local; Galicia.

Fecha de recepción: 31 de mayo de 2019

Fecha de aceptación: 24 de febrero de 2020

* Facultad de Filología. Departamento de Sociología. Universidade da Coruña. E-mail: iria.caamano@udc.es

** Facultad de Sociología. Universidade da Coruña. E-mail: mandrade@udc.es

*** Facultad de Filología. Departamento de Sociología. Universidade da Coruña.E-mail: antonia.perezg@udc.es 


\title{
Marine tourism as an option for sustainable local development based on female empowerment
}

\begin{abstract}
Marine tourism has become a tourist reference with more than two decades of international expansion and continuous growth. In this context, the present work aims to study marine tourism as an option for sustainable local development through female empowerment. The study has been based on semi-structured interviews with women who lead marine tourism projects in Galicia and on a content analysis of the news on the treatment that the press gives them. The results show that most of the projects are innovative, diversified, participatory and responsible. It is found that, despite the evident progress, it is necessary to further promote female entrepreneurship in the field of marine tourism, in addition to promoting their presence and social projection through the media.
\end{abstract}

Keywords: marine tourism; female entrepreneurship; fishing sector; local development, Galicia.

\section{INTRODUCCIÓN}

La evolución de las condiciones socioeconómicas, políticas y medioambientales que afectan a la actividad pesquera en la Unión Europea y, de forma específica a España y Galicia, han generado una situación de profunda crisis del sector (Molina et al., 2010; Miret-Pastor et al, 2015). Por ello, urge poner en marcha estrategias de diversificación que refuercen las economías locales proporcionándoles fuentes de ingresos complementarias (Farnet, 2011; Moreno-Muñoz y García-Marín, 2019). En este complejo escenario, la reorientación productiva de la pesca con fines turísticos se convierte en un valioso ejemplo de revitalización y desarrollo litoral sostenible (Howard y Pinder, 2003; Molina et al., 2010; Pardellas et al., 2011; Ling y Chiao, 2017; Herrera-Racionero et al., 2018; Moreno, 2018b) en el que la participación activa de las trabajadoras del mar se ha ubicado en la vanguardia (Martínez García, 2017).

Gracias a la terciarización del sector pesquero ha sido posible conservar elementos del patrimonio cultural marítimo (material e inmaterial) que, de otro modo, habrían desaparecido (Howard y Pinder, 2003; Doyon, 2015;Gràcia, 2016; Jiménez y García, 2018). A través del proceso de patrimonialización la cultura marinera, las instalaciones pesqueras y, la gastronomía local basada en productos del mar, éstos han conseguido convertirse no solo en recursos patrimoniales per se sino también en recursos económicos que promueven el desarrollo (Ling y Chiao, 2017;Rogelja y Janko, 2017: Jiménez y García, 2018).

En este proceso conservacionista, el turismo marinero ha contribuido en gran medida a promocionar el valor cultural de la pesca y a la conservación del patrimonio y de la identidad (Claesson, 2011; Jiménez y García, 2018) pero no se debe de olvidar el relevante rol desempeñado históricamente por las mujeres marineras consideradas "guardianas" 
de las tradiciones pesqueras (Nadel-Klein, 2000), especialmente en lo que se refiere a la cultura inmaterial.

Bajo estas consideraciones, el desarrollo del turismo marinero ha sido posible gracias a la apuesta realizada desde la Administración, el sector turístico y las cofradías (Chen, 2010; Herrera-Racionero et al., 2018; Moreno, 2018a), sin olvidar el contexto favorable del propio mercado (Padin y Aboy, 2010; Pardellas y Padín, 2013; Bender, 2015; Voyer et al., 2017; Lafuente, 2019).

Por otro lado, el emprendimiento turístico ha recibido una atención limitada en la literatura académica (Solvoll et al., 2015; Movono y Dahles, 2017; Power, et al., 2017, Mottiara et al., 2018) a pesar de sus reconocidos impactos sociales, medioambientales y económicos en el desarrollo local y de su destacado papel tanto para el empoderamiento de las mujeres (Datta y Gailey, 2012; Kimbu y Ngoasong, 2016) como para la promoción de la igualdad de género (OMT, 2011).

En efecto, el fomento del emprendimiento en general y el emprendimiento femenino en particular se ha convertido en una opción clave de los programas de incentivación económica, desarrollo rural e incluso en igualdad de oportunidades. Así, al amparo de los Grupos de Acción Local Pesquera (GALP), surgen en España diversas iniciativas de turismo marinero que se han convertido en pioneras, tanto a nivel empresarial como a nivel asociativo.

En base a este marco del emprendimiento femenino en espacios rurales y más concretamente en zonas litorales de pesca, el objetivo general del presente trabajo se ha centrado en estudiar el turismo marinero gallego como opción de desarrollo local desde el enfoque de la sostenibilidad y el empoderamiento femenino.

En Galicia existe una relación histórica con el mar y el sector pesquero a nivel cultural, social y económico (Martínez García, 2019). Así mismo, el emprendimiento en el ámbito del turismo tiene posibilidades de convertirse en agente de cambio y en motor de desarrollo social y económico, así como en un instrumento de puesta en valor de los numerosos recursos de las comunidades rurales pesqueras (Patiño, 2016).

Para cumplir con los objetivos específicos de la presente investigación se ha recopilado y analizado diversa información, tanto de carácter secundario como primario, mediante un estudio cualitativo a través de la realización de entrevistas en profundidad semiestructuradas a mujeres implicadas que lideran proyectos en el sector profesional objeto de estudio, cuyo fin es profundizar en los objetivos de los proyectos empresariales, así como en la percepción del empresariado femenino sobre el impacto del turismo marinero en el desarrollo local, desde la perspectiva de la sostenibilidad.

También se ha aplicado un análisis de contenido cualitativo-cuantitativo, a través de la prensa escrita durante los años 1990-2020 a través de la herramienta de búsqueda FACTIVA, para determinar la presencia del turismo marinero en Galicia y la representación social del emprendimiento femenino en este contexto.

Con ello, el artículo se estructura de la siguiente manera: primeramente, se expone el marco teórico del estudio haciendo hincapié en el rol de los GALP en el impulso del turismo marinero, así como en el papel de las mujeres emprendedoras; seguidamente se describe la metodología y se muestran los resultados más significativos. Por último, se plantean las principales conclusiones. 


\section{LA SINGULARIDAD DEL TURISMO MARINERO: LOS GALPY EL EMPREN- DIMIENTO TURÍSTICO FEMENINO}

Con la finalidad tanto de mejorar la calidad de vida del colectivo que trabaja en el mar, así como de reforzar la economía de las localidades costeras en el contexto de la crisis social, económica y ambiental que está sufriendo el sector pesquero, se están promoviendo, desde todos los ámbitos (internacional, nacional, autonómico y local), diferentes iniciativas de diversificación. En este sentido, las posibles sinergias entre turismo y pesca no han pasado desapercibidas para las cofradías de pescadores, ni para la Administración, ni para el sector turístico (Chen, 2010;Pardellas y Espejo, 2013; Herrera-Racionero et al., 2018). Ha surgido de este modoun tándem perfecto entre el turismo y la pesca que se ha denominado, en términos generales, turismo marinero.

El turismo marinero se propone así como alternativa a la crisis del sector y como fuente para el desarrollo territorial sostenible de los territorios costeros con tradición pesquera (Molina et al., 2010; Moreno et al., 2016; Ling y Chiao, 2017; Herrera-Racionero et al, 2018; Khakzad, 2018), a la vez que representa una propuesta innovadora y alternativa con potencial en el mercado turístico (Pérez y Espejo, 2012;Padín et al., 2016; Proyecto Sagital, 2017). A pesar de que no puede visualizarse como la solución definitiva a las dificultades estructurales a las que se enfrenta la pesca en ciertos territorios, está ayudando a mejorar las condiciones de vida de estas poblaciones costeras y contribuye a fomentar una mejor gestión y comprensión de los recursos pesqueros locales (Farnet, 2011; Claesson, 2011;Khakzad y Griffith, 2016;Ling y Chiao, 2017). Sin dudael patrimonio, la cultura y el turismo están, hoy en día, totalmente interrelacionados (Jiménez y García, 2018).

Dentro de las actividades principales que es posible desarrollar al amparo de la tipología turística "turismo marinero" se encuentran, por ejemplo, las visitas a las lonjas, puertos, museos... (Padin y Aboy, 2010), visitas a sitios históricos como faros, edificios, pueblos costeros... (Claesson, 2011), la pesca-turismo como una de las actividades más singulares (Moreno, 2018b) y, por supuesto, toda la parte inmaterial que permite conocer formas de vida, tradiciones, artes y oficios ( Jiménez y García, 2018).

El turismo marinero es una tipología turística considerada de bajo impacto (Farnet, 2013) que, además, fomenta la implicación de los residentes en el desarrollo turístico (Chek et al., 2018) y es considerada sostenible desde el triple enfoque (medioambiental, social y económico).

En este entorno de crisis, y con el apoyo financiero del FEMP a través de su Eje 4, ${ }^{1}$ aparecen en Europa y en España diferentes iniciativas encaminadas a crear un incipiente turismo marinero (Molina et al., 2010) que sondesarrolladas generalmente gracias al impulso de Cofradías de Pescadores, empresas privadas del ámbito turístico-hostelero, Ayuntamientos y Grupos de Acción Local Pesqueros² (GALP) (Moreno, 2018b). En este contexto, y al amparo de los GALP, se pueden diferenciar proyectos de carácter produc-

\footnotetext{
1 El eje 4 es el relativo al "Desarrollo sostenible de las zonas de pesca"

2 Los GALP (Grupo de Acción Local Pesquera) se crean al amparo del Reglamento 508/2014 dando continuidad a los GAC (Grupo de Acción Costera) creados al amparo del Reglamento 1198/2006.
} 
tivo, no productivo y de cooperación ${ }^{3}$. En referencia a los dos últimos, tal y como indica Khakzad (2018), la conservación del patrimonio marítimo a menudo es llevada a cabo por iniciativas de carácter voluntario y no comercial, simplemente con el fin de proteger, preservar y promocionar la cultura (material e inmaterial) vinculada al sector pesquero.

A continuación, con el fin de comprender mejor el entorno en el que se configura el turismo marinero en España, se considera oportuno profundizar más en el papel desarrollado por los GALP. En este sentido, a nivel interno, los GALP se configuran como asociaciones público-privadas formadas principalmente por representantes de los sectores pesquero y acuícola, además de por otros miembros de la comunidad local, que actúan como dinamizadores del territorio para fomentar el emprendimiento, la economía azul, la lucha contra el cambio climático, etc. Concretamente estas asociaciones están integradas y representadas por los siguientes sectores ${ }^{4}$ : sector pesquero, sector social, sector económico y sector público. Cada uno de los GALP tiene competencia para definir e implementar su propia Estrategia de Desarrollo Local Participativo (EDLP), convirtiéndose así en responsables de la planificación y dinamizadores de los territorios donde se ubican asumiendo la responsabilidad directa de la gestión y aplicación del Fondo Europeo Marítimo y de Pesca (FEMP).

De esta manera, los GALP representan un nuevo sistema de gobernanza territorial más complejo, plural e inclusivo, con nuevas fórmulas de gestión más descentralizadas y fundamentadas en un enfoque ascendente o bottom-up (Felicidades y Piñeiro, 2017) que ejercen a la vez como un importante vehículo para incrementar la visibilidad del papel de las mujeres en el sector pesquero (REMSP, 2017), así como para el desarrollo turístico.

En España, para el período de programación 2014-2020, hay un total de 41 GALP distribuidos de la siguiente manera: Andalucía (7), Asturias (7), Baleares (2), Canarias (7), Cantabria (2), Cataluña (2), Comunitat Valenciana (4), Galicia (8), Murcia (1) y País Vasco (1). Todos ellos se aúnan en la Red Española de Grupos de Pesca (REGP) dependiente de la Dirección General de Ordenación Pesquera y Acuicultura de la Secretaría General de Pesca del Ministerio de Agricultura, Pesca y Alimentación.

La Ley 11/2008 de 3 de diciembre de Pesca de Galicia fue la primera normativa autonómica que definía y regulaba el turismo marinero. Años después, en el 2012, se editó una guía de turismo marinero que aunaba toda la información sobre las actividades y empresas relacionadas, no solamente con la actividad de la pesca-turismo. Todo ello ha propiciado que Galicia sea la autonomía más prolífica en número de iniciativas (CETMAR, 2010; Moreno, 2018) y que en el año 2020 haya liderado la ejecución presupuestaria en el conjunto del Estado. La actual programación la distribución de los GALP gallegos se recoge en la Figura 1.

3 Tal y como se recoge en la normativa de los GALP los proyectos productivos se definen como actividades económicas tendentes a la producción de bienes y servicios y que suponen una creación y/o mantenimiento de empleo; los proyectos no productivos son de interés público que, constituyendo una actividad económica, no inciden sobre el régimen de competencia en el territorio de que se trate; proyectos de cooperación es cuando las entidades concurren conjuntamente.

4 Sector pesquero: asociaciones y entidades de interés colectivo pesquero, marisquero y acuícola con personalidad jurídica propia; b) Sector social: asociaciones socioculturales, deportivas, ecologistas, recreativas y educativas, asociaciones de mujeres, asociaciones relacionadas con la inclusión social y otras similares; c) Sector económico: asociaciones de empresarios y empresarias, asociaciones de agentes económicos y organizaciones sindicales; y d) Sector público: integrado por las administraciones públicas de ámbito local y entidades del sector público vinculadas o dependientes de estas. 


\section{Figura 1 \\ DISTRIBUCIÓN DE LOS GALP EN GALICIA}

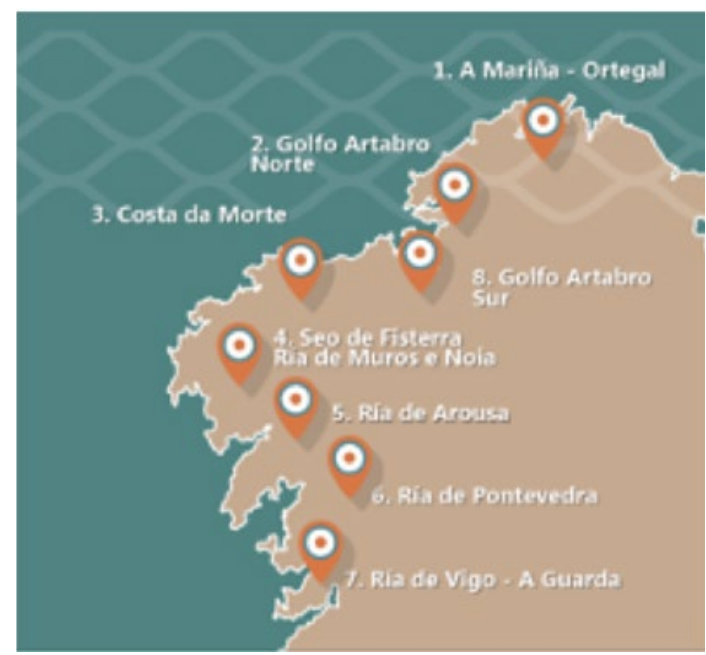

Fuente: https://galp.xunta.gal/

Cabe añadir que el turismo marinero en España, a pesar de que ha avanzado en los últimos años, aún se encuentra en una fase incipiente y, en todo caso, es muy irregular (Pardellas yPadín, 2013; Miret-Pastor et al, 2015; Herrera-Racionero et al, 2018). Algunas de las iniciativas impulsadas han tenido corto recorrido debido a diversos inconvenientes culturales, financieros y, sobretodo, por una legislación restrictiva (Miret-Pastor et al., 2018; Lafuente, 2019), pero en otros casos han sabido adaptarse al mercado turístico.

En primer lugar, en cuanto a los inconvenientes culturales, cabe mencionar que los proyectos han sido acogidos de diferente manera por los actores implicados según la zona pero, por norma general, se han consolidado como productos turísticos singulares, incrementando, por consiguiente, el número de turistas y generando ingresos en las comunidades costeras. La ausencia de estadísticas impide hacer una valoración objetiva de este crecimiento, pero la demanda existe, puesto que cada vez son más las empresas que se dedican a ofrecer actividades turísticas relacionadas con la cultura marítima (La Voz de Galicia, 26/08/2018).

No obstante, tal y como advierte Alegret (2013), el principal peligro de la transformación que se está produciendo en el patrimonio marítimo es la mercantilización de la cultura marítima, irrumpiendo con fuerza en la oferta cultural y gastronómica (parte integrante del patrimonio inmaterial y muy activa en las políticas culturales de turismo). En esta línea, también hay que subrayar el hecho de que ciertos sujetos implicados en el ámbito marítimo pesquero no conciben que su cultura marítima sea tratada como recurso turístico (Jiménez y García, 2018), lo cual supone una gran limitación.

En segundo lugar, los problemas financieros se han visto solventados gracias al apoyo financiero del FEMP y a través de las ayudas de financiación gestionadas por los GALP, de 
manera que han favorecido en España el surgimiento de diferentes iniciativas encaminadas a crear un incipiente turismo marinero (Molina et al., 2010).

En tercer y último lugar, la existencia de una legislación restrictiva y poco precisa obstaculiza el carácter definitorio de la actividad. En concreto, la ley 33/2014 de 26 de diciembre por la que se modifica la Ley 3/2001 de 26 de marzo, de Pesca Marítima del Estado Español reconoce explícitamente esta actividad e introduce los conceptos de "diversificación pesquera y acuícola", así como los de "turismo pesquero o marinero", "turismo acuícola" y "pesca-turismo" en la normativa nacional. Aunque a nivel autonómico, a excepción de Cataluña, Galicia, Baleares y Canarias, todavía buena parte de las iniciativas siguen adoleciendo de la falta de un marco legal apropiado (Pardellas y Padín, 2013; Herrera-Racionero et al, 2018; Lafuente, 2019), provocado, posiblemente, porque bajo la misma etiqueta se esconden actividades y realidades muy diferentes.

En este contexto, en la mayoría de las Comunidades Autónomas Españolas las mujeres de la costa son protagonistas de la actividad pesquera, adquiriendo una importancia socioeconómica decisiva en el sector, puesto que participan tradicionalmente en todas las actividades y procesos relacionados con la cadena productiva, desde el subsector extractivo hasta la comercialización final del producto (García y Zotes, 2006). De hecho, en las sociedades costeras tradicionalmente han adquirido un rol más progresista (Lorenzo y Martínez, 2003), con un marcado estereotipo que las define como más autónomas e independientes que en otros contextos (Broullón Acuña, 2010). Sin embargo, un aspecto clave a resaltar es la diferencia de representatividad por ramas, dado que algunos de los procesos en la cadena productiva del pescado adquieren un carácter eminentemente femenino (por ejemplo, las conserveras). Este reparto de tareas tiene consecuencias en la distribución de espacios y, con ello, en las condiciones laborales, en la visibilidad de los oficios y en el ejercicio del poder en estas comunidades (Nadel Klein, 2000; Martínez García, 2017). Se pone así de evidencia que la división sexual del trabajo en las comunidades marineras está claramente influida por el binomio de la frontera física entre tierra y mar, conformando así un dualismo jerárquico en el que se sostienen las desigualdades de género (Broullón, 2010).

La literatura confiere una creciente valoración de la función de la mujer dentro de las estrategias de desarrollo social y económico del medio rural a la vez que se considera que ejerce funciones de vital importancia y constituye un recurso propio del territorio y una posible ventaja comparativa que debe ser potenciada en términos de renta y empleo (Rico y Gómez, 2009; Osuna-Rodríguez et al., 2015). El importante y notable papel de la mujer en el desarrollo rural ha sido destacado frecuentemente en la literatura, pero más novedoso resulta el papel de la mujer emprendedora en este ámbito relacionado con el mar (Talón et al; 2014) recibiendo atención limitada a nivel académico (Solvoll et al., 2015; Movono y Dahles, 2017).

Concretamente, en el ámbito pesquero y acuícola las mujeres llevan años demostrando que poseen este carácter emprendedor. Estas iniciativas han dado respuesta a los desafíos y necesidades de sus respectivos entornos, han impulsado la conservación de los recursos, la creación de empleo y el desarrollo económico y social de los territorios costeros (REMSP, 2016). En el plan estratégico DIVERPES (2013-2020) también se recoge el importante papel de las mujeres como impulsoras del turismo marinero. En resumen, la mujer cons- 
tituye así un sujeto especialmente relevante para el desarrollo, no sólo económico, sino también social y cultural de las zonas rurales (Pérez Cabrera et al., 2017).

En un contexto en el que impera la necesidad de impulsar iniciativas de diversificación del sector pesquero, en busca de vías de ingresos complementarios a través de nuevas ideas de negocio basadas en segmentos con potencial de crecimiento, el turismo emerge como una oportunidad laboral y de desarrollo local también para el colectivo femenino. La evidencia muestra cómo el sector turístico proporciona empleo a las mujeres y mejorapotencialmente su independencia económica y social (Kimbu y Ngoasong, 2016) y, en este sentido, su iniciativa empresarial en materia de diversificación ha sido especialmente destacada en el ámbito del turismo marinero (Gessa y Toledano, 2011).

En los últimos años se observa que el colectivo de las mujeres está adquiriendo un protagonismo creciente en el ámbito rural, también costero, a través del auto emprendimiento (Rico y Gómez, 2005) y, además, se ha producido un aumento del propio (auto) reconocimiento de las mujeres del mar pudiendo hablar de una "experimentación de empoderamiento", tal y como indica Martínez García (2017).En esta línea, estudios previos sugieren que el emprendimiento social constituye un factor clave, tanto para la creación y diversificación de la actividad empresarial y el crecimiento económico, como para la emancipación y el empoderamiento de las mujeres (Datta y Gailey, 2012; Kimbu y Ngoasong, 2016).

En este sentido, cabe reconocer que el papel de las mujeres como vectores del emprendimiento social en turismo se está incrementando (Kimbu y Ngoasong, 2016) y que, en las comunidades pesqueras, destaca la iniciativa emprendedora femenina en este ámbito, su alta capacidad de innovación y su apuesta por la diversificación (REMSP, 2017) al perseguir simultáneamente estas actividades económicas y sociales, es decir, satisfacer las necesidades del mercado y contribuir al desarrollo local.

En base a estas consideraciones, se podría incluso catalogar a este tipo de emprendimiento femenino en las zonas pesqueras como de emprendimiento pro-sostenible ("sustainopreneurship") que, como señalan Gessa y Toledano (2011), sigue constituyendo una novedosa línea de investigación que se caracteriza por su orientación prioritaria hacia la preservación de la naturaleza y el apoyo a la comunidad local a través de la búsqueda y explotación de oportunidades que se materializan en nuevos productos, procesos, servicios, etc. Más específicamente, es el tipo de emprendimiento que se caracteriza por adoptar un enfoque de abajo a arriba (bottom-up), hacia la interacción y cooperación de los diferentes agentes (pequeñas empresas e instituciones públicas), sistemas (empresarial, social y natural) y recursos de la comunidad, para analizar e implantar soluciones locales que hagan frente a los problemas del entorno (Abrahamsson, 2008).

Así,desde las políticas de desarrollo rural se ha apostado por fomentar la promoción y el apoyo a las iniciativas empresariales impulsadas por mujeres con el doble objetivo de crear alternativas laborales y de aumentar la participación laboral femenina y, por consiguiente, conseguir una mayor diversificación de la economía rural (Alario y Morales, 2016).

En todo caso, cabe poner de relieve que los GALP han ejercido un papel fundamental en el respaldo de la iniciativa empresarial femenina (Martínez García, 2017) y han liderado la puesta en marcha de numerosos proyectos empresariales de éxito entre las que se 
encuentran iniciativas turísticas con un marcado carácter y enfoque marinero, ya sea a través de colectivos, agrupaciones profesionales o bien de manera individual (REMSP, 2017).

Varios de estos proyectos fueron reconocidos por la Comisión Europea como "proyectos estrella"por su contribución al propósito de buenas prácticas a nivel europeo en el marco del Desarrollo Local. En el caso gallego cabe mencionar en el ámbito turístico y a nivel asociativo casos como el de GUIMATUR de Cambados (REMSP, 2017), las Mariscadoras de Carril quienes realizan visitas, charlas y talleres y AMARTUMAR (Redondela) quienes ofrecen diferentes rutas turísticas (ruta a pie, ruta vive el marisqueo a flote, ruta del choco, ruta del puerto y ruta del Xeito ${ }^{5}$ ) así como información cultural, gastronómica y turística sobre el mundo del mar (REMSP, 2020).

Estos ejemplos demuestran la gran capacidad dinamizadora de la población femenina como promotora de proyectos innovadores a través de los cuales dan respuestas a las demandas del sector y a las suyas propias tanto de manera individual como especialmente a nivel colectivo (REMSP, 2017). Las posiciones de las trabajadoras del mar respecto a la diversificación se vinculan de este modo a la noción del bien común que se manifiesta en el sostenimiento del sector pesquero y del entorno comunitario y se aleja de las posiciones individualistas y emprendedoras de las instituciones (Martínez García, 2017).

\section{OBJETIVOS Y DISEÑO METODOLÓGICO}

El objetivo general del presente trabajo se basa en estudiar el turismo marinero gallego como opción de desarrollo local desde el enfoque de la sostenibilidad y el empoderamiento femenino. Los objetivos específicos se centran, por una parte, en profundizar en las metas u objetivos de los proyectos empresariales, así como en la percepción del empresariado femenino sobre el impacto del turismo marinero en el territorio a nivel de desarrollo local desde la óptica de la sostenibilidad. Por otra parte, se propone analizar la presencia de las actividades relacionadas con el turismo marinero en Galicia y la proyección social del emprendimiento femenino a través de la prensa escrita.

La metodología aplicada en el presente estudio es de carácter exploratorio- descriptivo y se basa en un análisis de datos de tipo mixto a través de la realización de un total de 10 entrevistas en profundidad semi-estructuradas, la revisión y recopilación de datos cualitativos y cuantitativos a través de fuentes secundarias y en un análisis de contenido cualitativo-cuantitativo de noticias recogidas de la prensa escrita gallega a través de la herramienta FACTIVA. Se explican seguidamente en detalle las fases metodológicas de investigación de recogida y tratamiento de la información:

$1^{\text {a }}$ Fase: se ha recopilado información de fuentes secundarias de tipo cualitativocuantitativo. En este sentido, la información extraída de la web oficial de los GALP ${ }^{6}$, ha permitido contextualizar el ámbito y el objeto de estudio y realizar un exhaustivo inventario de las actividades empresariales femeninas ligadas al sector pesquero.

$2^{\text {a }}$ Fase: se basa en la realización de 10 entrevistas en profundidad semi-estructuradas a mujeres que han desarrollado proyectos empresariales seleccionados por su represen-

5 Se trata de una jornada de pesca artesanal de sardina.

6 Web Oficial de los GALP en Galicia: https://galp.xunta.gal/ 
tatividad, las cuales fueron codificadas desde E.1 a E.10, respetando su anonimato. La selección de las informantes se ha realizado a través de un muestreo por conveniencia, ateniéndose a los siguientes criterios: 1) ser proyectos productivos relacionados con el sector turístico marinero, 2) que estuviesen representados los 8 GALP, cubriendo de esta forma la totalidad del litoral gallego y 3) que fuesen proyectos en activo en el período en el que se lleva a cabo la investigación.

Tabla 1

MUESTRA

\begin{tabular}{|c|c|c|c|}
\hline Entrevistada & Actividad turística & GALP & Año apertura \\
\hline E.1 & Casa Rural & GALP 7 & 2017 \\
\hline E.2 & Restaurante & GALP 3 & 2018 \\
\hline E.3 & Cafetería gastronómica & GALP 2 & 2019 \\
\hline E.4 & Turismo Activo & GALP 6 & 2019 \\
\hline E.5 & Visitas Guiadas & GALP 5 & 2018 \\
\hline E.6 & Hotel & GALP 6 & 2017 \\
\hline E.7 & Casa Rural & GALP 4 & 2017 \\
\hline E.8 & Visitas Guiadas & GALP 3 & 2010 \\
\hline E.9 & Hotel & GALP 1 & 2017 \\
\hline E.10 & Turismo Activo & GALP 5 & 2017 \\
\hline
\end{tabular}

Fuente: Elaboración propia.

Las 10 entrevistas son grabadas, garantizando el anonimato de las mujeres entrevistadas y transcritas íntegramente. Para la elaboración del guión de la entrevista se ha seguido el criterio de aplicación de las tres dimensiones que plantean Fuentes y Sánchez (2010) para abordar la figura del emprendedor: perfil demográfico, perfil psicológico y perfil sociológico.

El análisis de contenido de las entrevistas se apoya en el software del programa ATLAS.TI (Versión 8.1.3) teniendo en cuenta las variables categóricas de análisis encuadradas en tres dimensiones temáticas, que responden a los objetivos propuestos:

- Radiografía del emprendimiento turístico femenino al amparo de las ayudas de los GALP.

- Objetivos del proyecto empresarial.

- Impactos de los proyectos en el desarrollo local desde la perspectiva de la sostenibilidad. 
Con relación al perfil sociodemográfico de la muestra de mujeres emprendedoras entrevistadas (Véase Tabla 2), se puede observar que una gran mayoría se concentra entre los 30 y 50 años $(70 \%)$, con un nivel de estudios medio-alto, pero casi sin formación específica en turismo (10\%).

\section{Tabla 2 \\ PERFIL SOCIODEMOGRÁFICO DE LA MUESTRA ENTREVISTADA}

\begin{tabular}{|l|l|}
\hline \multicolumn{1}{|c|}{ Características Sociodemográficas } & \multicolumn{1}{|c|}{ Porcentajes } \\
\hline Edad & $\begin{array}{l}\text { Menos de 30: 0\% } \\
\text { Entre 30 y 40: } 40 \% \\
\text { Entre 40 y 50: 30\% } \\
\text { Más de 50: 30\% }\end{array}$ \\
\hline Formación & $\begin{array}{l}\text { Básicos: } 20 \% \\
\text { FP: } 40 \%\end{array}$ \\
\hline Estudios en turismo & Universitarios: $40 \%$ \\
& Sí: $10 \%$ \\
& No: $90 \%$ \\
\hline
\end{tabular}

Fuente: Elaboración propia.

$3^{\text {a }}$ Fase: finalmente se ha realizado un análisis de contenido cualitativo-cuantitativo de las noticias aparecidas en la prensa escrita a través de la herramienta de búsqueda FACTIVA, ${ }^{7}$ con la finalidad de determinar la presencia de informaciones relacionadas con el turismo marinero y la importancia que la mujer emprendedora tiene en el eco informativo social.

La investigación se ha organizado en dos secuencias: primeramente, se ha medido la presencia por años y por comunidades autónomas; seguidamente se ha analizado la información sobre el turismo marinero, para cuyo análisis cualitativo se emplea también el programa ATLAS.TI como herramienta de apoyo.

La muestra se ha generado por la indexación que determina FACTIVA con el descriptor "turismo marinero" en todos los periódicos de su universo. La cohorte de temporalización establecida va desde el 1 de enero de 1990 al 1 de junio de 2020, teniendo en cuenta que la orden de búsqueda en la plataforma ha sido establecida como "todas las fechas" posibles hasta la fecha concreta de registro.

La búsqueda a través de FACTIVA arroja un total de 618 noticias para Galicia, por lo que el análisis se aplica sobre el censo total explorado por la herramienta de búsqueda. Los medios rastreados han sido (ver Figura2): 2 agencias de noticias (Europa Press y Efe), 15 diarios impresos (La Voz de Galicia, Faro de Vigo, La Opinión A Coruña, Diario de Pontevedra, El Progreso, El País, ABC, El Correo Gallego, La Gaceta (Español), El

7 FACTIVA se define como una base de datos comercial y corporativa de información de la prensa ofrecida por Dow Jones (proveedor de bases de datos) que incluye cerca de 35.000 fuentes procedentes de 200 países y abarca diarios, revistas e imágenes de más de 400 agencias de noticias. Recuperado de: http://www.factiva.com 
Mundo, Expansión, 20 Minutos, La Vanguardia, La Voz de Cadiz y Alimarket-Hostelería) y 7 diarios digitales (Faro de Vigo Online, La Opinión A Coruña Online, ABC.es, Crítica Online, El Diario Vasco Online, La vozdigital.es y La Información.com).

\section{Figura 2 \\ DISTRIBUCIÓN DE LAS NOTICIAS SEGÚN LOS MEDIOS ANALIZADOS}

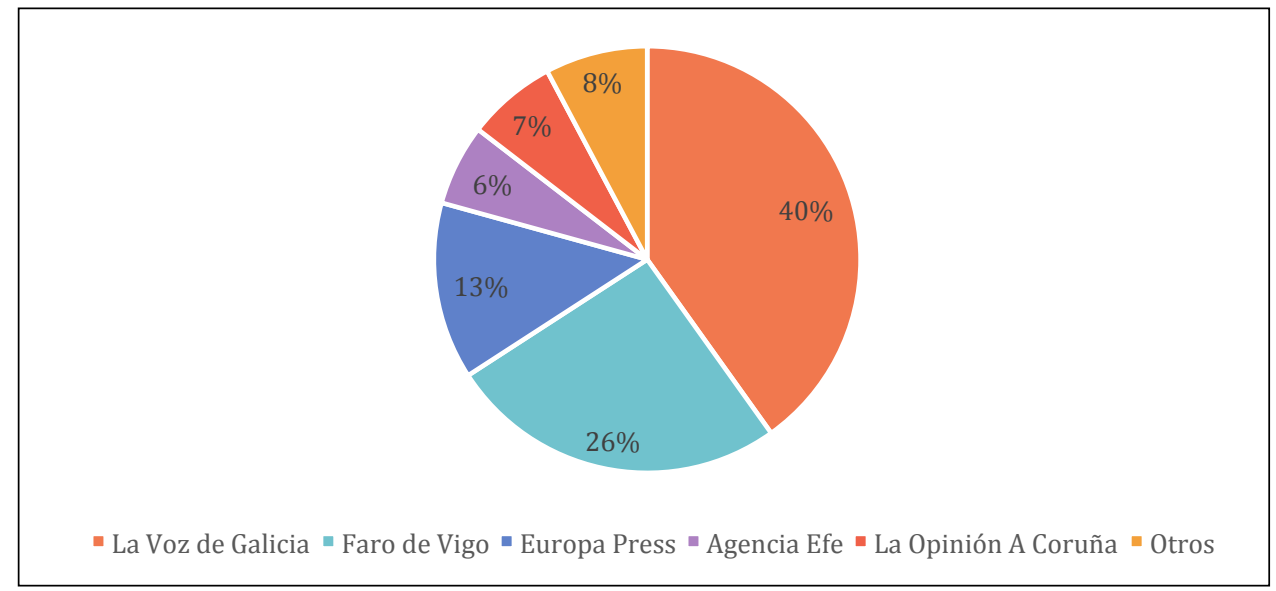

Fuente: Elaboración propia, basado en los datos registrados por FACTIVA

Nota: La variable categórica "Otros" incluye aquellos medios que no superan el 1,5\% cada uno de ellos.

\section{RESULTADOS Y DISCUSIÓN}

\subsection{Percepción del empresariado femenino sobre el impacto del turismo marinero en el territorio}

En este primer punto, se aborda el análisis desde las variables categóricas planteadas, delimitadas en dimensiones temáticas y que se corresponden con los objetivos descritos.

A continuación, y para entender mejor el desglose de los temas tratados en las entrevistas realizadas en el presente trabajo, se procede a realizar un análisis de contenido de las palabras claves (keywords) utilizadas por las propias empresarias lo cual permite contextualizar y estructurar sus testimonios. A través de la nube de tags realizada se han identificado los conceptos más repetidos y, por tanto, los más importantes. Tal y como se muestra en la Figura 3, destacan las siguientes palabras clave: turismo ( $\mathrm{N}=65)$, mujeres $(\mathrm{N}=56)$, proyecto $(\mathrm{N}=50)$ y pesquero $(\mathrm{N}=41)$. Además, otros conceptos interrelacionados son: emprender $(\mathrm{N}=36)$, territorio $(\mathrm{N}=35)$, experiencias $(\mathrm{N}=22)$ y participación $(\mathrm{N}=22)$.

En línea con estudios previos, los resultados corroboran que el producto turístico marinero emerge como complemento de los ingresos de aquellas comunidades costeras cuya principal fuente de ingresos sigue siendo la pesca pero donde es necesario apostar por actividades alternativas como el turismo (Chen, 2010; Padín y Aboy, 2010; Kaltenbor et. al., 2012; Chen y Chang, 2017; Ling y Chiao, 2017; Martínez García, 2017; Voyer et 
al., 2017; Jiménez y García, 2018; Moreno, 2018). Además, también se refleja el papel de las mujeres como emprendedoras y promotoras dado que están favoreciendo la diversificación económica de la actividad pesquera, así como la creación de riqueza y empleo mejorando, por lo tanto, la competitividad del sector (Gessa y Toledano, 2011). También aparecen mencionados, aunque con menor peso, términos como conciliación $(\mathrm{N}=14)$ y discriminación $(\mathrm{N}=15)$.

"La crítica es mucho más evidente hacia la mujer. En el entorno cercano también se percibe esa crítica o visión machista, incluso entre las mujeres mayores del entorno". (E.1)

\section{Figura 3 \\ NUBE DE PALABRAS}

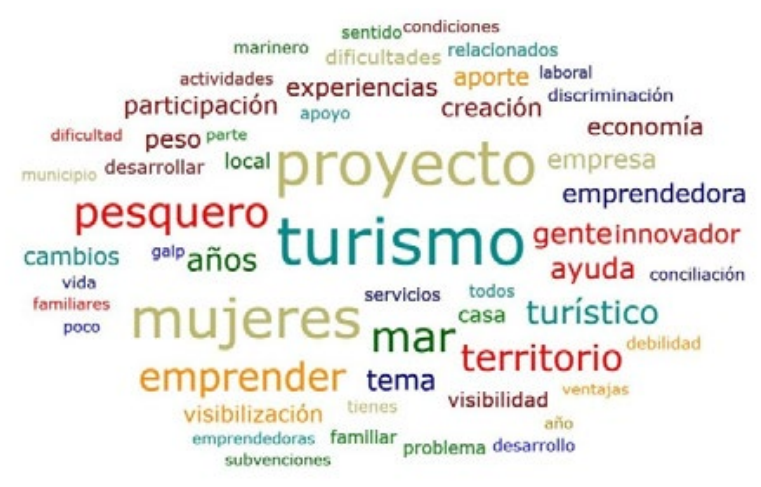

Fuente: Elaboración propia a partir de Atlas.ti (8.1.3).

En resumen, la incorporación de la mujer como emprendedora dentro del sector turístico, y concretamente en el turismo marinero, no resulta fácil pero, según los testimonios obtenidos, ha contribuido de manera significativa al reconocimiento laboral y también a una mayor independencia económica. Cabe destacar que, en conexión con lo recogido en otras investigaciones (Nadel-Klein, ,2000; Rico y Gómez, 2009), el trabajo realizado por las mujeres en el mar se suele concebir como una contribución económica complementaria a la economía doméstica sin tener reconocido su estatus laboral, frente a la del hombre como sustentador principal. En esta ocasión, la entrevistada E.10 lo explica de la siguiente manera:

“...para ellas es un complemento, el ir a mariscar les sirve para pagar la seguridad social y tener dinero para hacer la compra semanal, pero no lo ven como un puesto de trabajo" (E.10) 
Precisamente es necesario reiterar la complicada situación en la que se encuentra la pesca, lo cual también ha comportado una falta de interés por parte de las nuevas generaciones en dedicarse al sector pesquero decantándose por el sector servicios (Martínez y Moreno, 2014; Lafuente, 2019). De hecho, el turismo marinero en sus orígenes surgió como un tándem entre la actividad pesquera y el turismo y no estaban concebidos como actividades excluyentes sino complementarias (Martínez y Moreno; 2013; Pardellas y Padín, 2013; Voyer et al., 2017; Jiménez y García, 2018; Lafuente, 2019). Reforzando esta idea, en el propio plan estratégico DIVERPES (2013-2020) se aporta una definición de turismo marinero en el que considera requisito que sea una "actividad desarrollada por los colectivos de profesionales del mar, mediante contraprestación económica, orientadas a la valorización y difusión de las actividades y productos del medio marino, así como las costumbres, tradiciones, patrimonio y cultura marinera" (p.3). Aunque, en el propio informe, a continuación (p.4.) hablan de un turismo en zonas costeras donde se ofrecen actividades y productos ligados al medio pesquero. Sin embargo, a nivel legislativo en el caso concreto de Galicia no está aún establecido claramente. De hecho, tal y como confirman las entrevistadas E.8 y E.10., parece que resulta burocráticamente complicado materializar esta idea, a excepción de las actividades sin ánimo de lucro desarrolladas por las asociaciones al amparo de las cofradías. Así, gran parte de la oferta que se engloba como producto de turismo marinero es desarrollada por empresas turísticas (Véase más adelante la Figura 7).

Otra de las dificultades históricamente mencionadas sobre el turismo marinero es la débil y complicada colaboración entre los diferentes agentes implicados en su implementación (Padin y Aboy, 2010). Sin embargo, las propias mujeres entrevistadas enfatizan que la organización en asociaciones les ha permitido defender sus derechos y dar visibilidad a sus proyectos y a su trabajo. En línea con lo que menciona Martínez García (2017), la propia incorporación de las mujeres a estas estructuras participativas se la puede considerar una clara manifestación del incremento de su capital político y social, que se traduce asimismo en un mayor liderazgo e incremento de su incorporación en este tipo de proyectos de carácter comunitario. En esta ocasión matizan además que la creación de redes con otras empresas o mujeres de la zona les ha permitido extender su visibilidad en la sociedad y también en el propio mercado, lo cual siempre se valora teniendo en cuenta que una de las debilidades del turismo marinero es la escasa información existente sobre los productos y actividades ofertadas que, en ocasiones, no conocen ni los propios agentes implicados (Padin y Aboy, 2010).

"Tratamos de mantener una relación importante con las casas de turismo rural, especialmente para promocionarnos" (E.1)

"Desde la asociación se hace promoción y da visibilidad en ciertos foros y en redes sociales" (E.10)

Aunque se parte de la base de que cada una de las iniciativas empresariales analizadas tiene una repercusión transterritorial, es decir, no solo afecta de manera directa a su territorio más cercano, sino que su impacto se traduce, en general, en el destino Galicia, en el presente estudio también se ha considerado oportuno examinar al amparo de qué GALP 
se han desarrollado los proyectos concretos, dado que el desarrollo del turismo marinero en la costa gallega no es homogéneo (Padin y Aboy, 2010).

En este contexto, el turismo marinero surge como una oportunidad de diversificación en destinos ya consolidados, pero también como impulso en destinos emergentes. De los datos obtenidos (Ver Figura 7) se deduce que el mayor índice de emprendimiento femenino se sitúa al norte de Galicia, en concreto, en el Golfo Ártabro Norte (GALP 2) y en la Costa da Morte (GALP 3).

A nivel global, sin embargo, destacan el GALP 4. Fisterra-Ría de Muros-Noia seguido del GALP 1. A Mariña-Ortegal. Tras una somera revisión de la oferta turística en los 8 territorios, se confirman los efectos generados por estas ayudas, no sólo relacionados con la ampliación empresarial sino con la propia generación de un modelo de desarrollo turístico más enfocado a la puesta en valor de la cultura del mar (mayor presencia de una oferta de restauración, de alojamiento, actividades, etc., relacionadas con el mundo marítimo-pesquero).

Como ejemplo de lo expuesto, en el territorio que conforma el GALP 4 se ha promovido y facilitado la conservación de la cultura marítima desde diferentes perspectivas. Si bien es cierto que ya de por sí alberga pueblos de marcado carácter marinero, tanto en sus puertos como en las propias construcciones de sus casas (Finisterre, Corcubión, Muros, Porto do Son...) además, se pueden visitar instalaciones marítimas-turísticas como faros reconvertidos en hoteles, fábricas de salazón que ahora funcionan como restaurantes, lonjas visitables, visitas a los arenales con las mariscadoras/es y paseos en embarcaciones tradicionales (Véase Figura 4). Además, la oferta alojativa y de restauración adquiere un marcado carácter marinero a través de la decoración y de la promoción de la marca de calidad KMO que promueve el consumo de productos locales.

\section{Figura 4 \\ BALANDRO DEL AÑO 1916 JOAQUÍN VIETA}

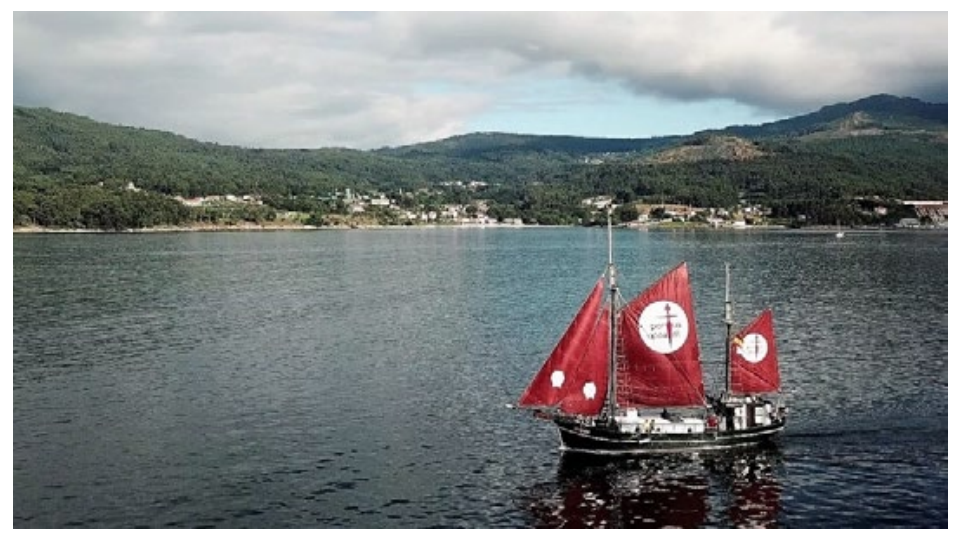

Fuente: Asociación Joaquín Vieta. 
Tabla 3

PORCENTAJES DE EMPRENDIMIENTO EN LAS ZONAS GALP

\begin{tabular}{|l|c|c|}
\hline \multicolumn{1}{|c|}{ GALP } & TOTAL & MUJERES \\
\hline GALP 1. A Mariña-Ortegal & $22(18,18 \%)$ & $5(10,56 \%)$ \\
\hline GALP 2. Golfo Ártabro Norte & $17(14,04 \%)$ & $11(23,92 \%)$ \\
\hline GALP 3. Costa da Morte & $20(16,53 \%)$ & $11(23,91 \%)$ \\
\hline $\begin{array}{l}\text { GALP 4. Fisterra-Ría de Muros- } \\
\text { Noia }\end{array}$ & $26(21,49 \%)$ & $7(15,22 \%)$ \\
\hline GALP 5. Ría de Arousa & $14(11,57 \%)$ & $6(13,04 \%)$ \\
\hline GALP 6. Ría de Pontevedra & $9(7,44 \%)$ & $3(6,52 \%)$ \\
\hline GALP 7. Ría de Vigo-A Guarda & $12(9,92 \%)$ & $3(6,52 \%)$ \\
\hline GALP 8. Golfo Ártabro Sur & $1(0,83 \%)$ & $0(0 \%)$ \\
\hline TOTAL & $121(100 \%)$ & $46(100 \%)$ \\
\hline
\end{tabular}

Fuente: Elaboración propia a partir de los datos de la web https://galp.xunta.gal/

Seguidamente, en la Figura 5 se muestra un mapa conceptual con las interrelaciones entre los tres factores clave que sintetizan el potencial del turismo marinero como elemento dinamizador del territorio en base a los discursos de las entrevistadas y que serán explicados a continuación en detalle:

\section{Figura 5 \\ FACTORES QUE IMPULSAN EL TURISMO MARINERO COMO DINAMIZADOR DEL TERRITORIO}
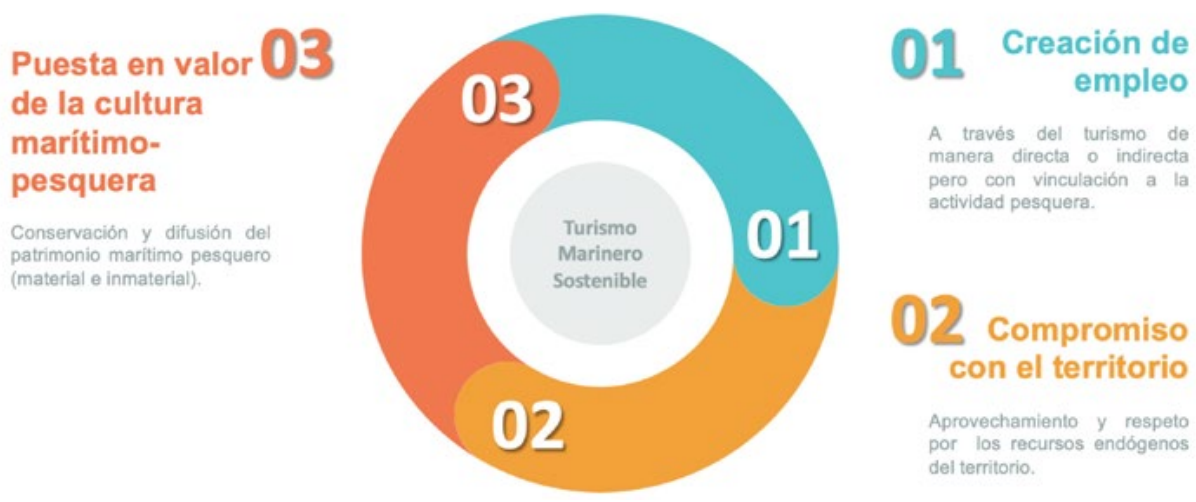

Fuente: Elaboración propia a partir del análisis de las entrevistas con ATLAS.TI 


\subsubsection{Creación de empleo}

Tal y como ya se ha descrito, el turismo marinero se considera una alternativa a la crisis del sector pesquero y se alza, por tanto, como una iniciativa que puede alentar el desarrollo económico de territorios situados en el litoral. Bajo estas consideraciones, se presenta la siguiente Figura 6 la evolución del emprendimiento (masculino y femenino) de aquellas empresas de turismo marinero impulsadas con ayudas del FEMP a través de los GALP en el territorio gallego a lo largo de los años 2016-2019. El estudio pone de manifiesto que, a pesar de que existen algunos datos sobre iniciativas surgidas previamente (en 2010 y 2011) en su etapa como GACs (Grupos de Acción Costera), las empresas turísticas impulsadas por los GALP gallegos fueron creadas mayoritariamente a partir de 2016 (un 97\%).

En total, de las 290 son $121^{8}$ las empresas turísticas que están relacionadas, de un modo u otro, con el patrimonio cultural pesquero, tangible e intangible. Así mismo, se observa que en 2019 se produce un importante aumento en el número de empresas lideradas por mujeres -con un total de 17 . No obstante, en términos globales, se puede considerar el año 2017 como el mejor año de emprendimiento femenino con un $28 \%$ de incremento. A pesar de que en estudios como los de Gessa y Toledano (2011) se afirma que la mujer puede desempeñar un papel importante en la contribución al desarrollo sostenible de las zonas pesqueras (Gessa y Toledano, 2011), los datos obtenidos señalan que, de momento, la presencia de emprendimiento femenino con iniciativas de turismo marinero en Galicia apenas representa un $20 \%$ de la totalidad, a lo que hay que añadir que, en algunos casos, los proyectos son liderados por ambos miembros de la pareja.

\section{Figura 6 \\ EVOLUCIÓN DEL EMPRENDIMIENTO 2016-2019}

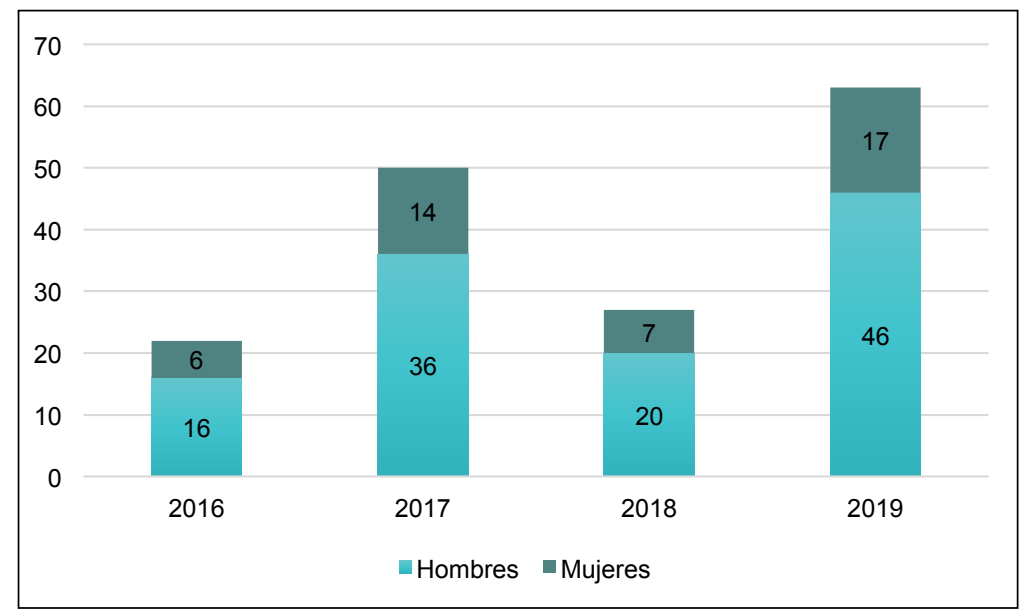

Fuente: Elaboración propia.

8 Los datos han sido recopilados de la propia página web del Galp: https://galp.xunta.gal/proxectosaprobados (Fecha de consulta: 15/01/2020) 
En todo caso, es preciso subrayar que la mano de obra de la mujer en las zonas rurales es fundamental para el inicio de nuevas actividades económicas dentro del proceso de diversificación productiva, para fijar población, aumentar las tasas de actividad, generar nuevos empleos y, en general, para impulsar de forma efectiva las nuevas estrategias de desarrollo en el ámbito rural (García y Baylina, 2000). En el caso del ámbito pesquero, las mujeres han participado activamente en el fomento de la dinamización empresarial aprovechando las nuevas oportunidades que han ido surgiendo (REMSP, 2016).

En base a este argumento, se confirma que la mayoría de las empresas analizadas plantean como objetivo principal, en su proyecto inicial, crear empleo en el territorio. No obstante, la mayoría son autónomas y pequeñas empresas (La Voz de Galicia, 26/08/2018).

\section{Figura 7 \\ SECTOR DE ACTIVIDAD}

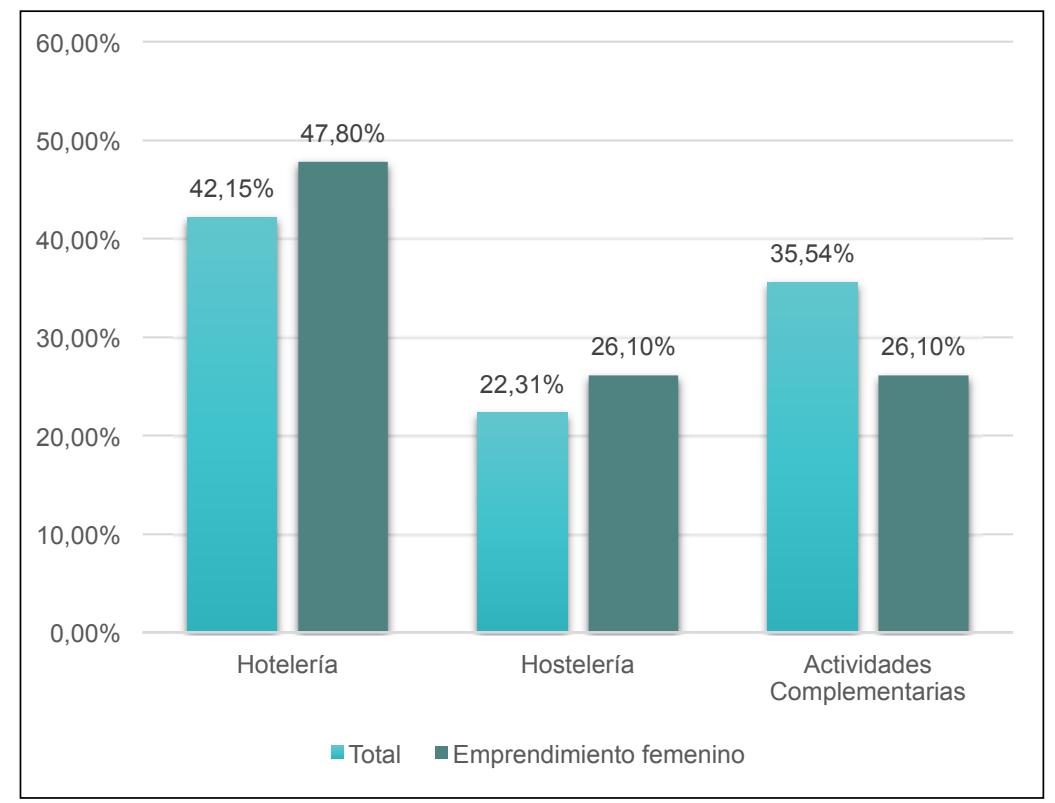

Fuente: Elaboración propia.

Tal y como se observa en la Figura 7, un análisis detallado del subsector elegido por las empresarias revela además que existe una gran concentración en el ámbito de la hotelería (un $47,8 \%$ frente al $42,15 \%$ del total) conformado principalmente por casas de turismo rural, pensiones y/o apartamentos turísticos. Esta inclinación, se debe posiblemente a que en los otros subsectores es más difícil conciliar, tal y como indica la entrevistada E.6. “... impensable poder emprender si eres madre de hijos pequeños" (E.6). Sin embargo, en la hotelería, según aclaran las entrevistadas, permite mayor facilidad para la conciliación frente a la hostelería u otrasactividades complementarias. 
"En nuestro caso nos permitió conciliar. Te permite tener a los críos en casa aunque intentamos no tenerlos mucho por si molestan a los clientes" (E.7. Casa Rural)

"Tengo una hija, tengo la suerte de tenerla conmigo siempre en mi trabajo" (E.9. Hotel)

"Encuentro dificultades para la conciliación y falta de comprensión por parte de clientes, proveedores, socios...”. (E.4., Turismo Activo)

\subsubsection{Compromiso con el territorio}

El compromiso con el territorio, desde el punto de vista de la sostenibilidad, se hace palpable a través de las afirmaciones de compromiso y responsabilidad con el medio ambiente de las entrevistadas, como las que se recogen a continuación:

"Tenemos una finca detrás donde cultivamos nuestros productos para abastecer al restaurante (...) un peso importante de la carta está relacionado con el mar, además de producto de proximidad. Toda nuestra oferta está basada en lo sostenible y ecológico." (E.1.)

"Nuestra oferta está basada en productos frescos y tradicionales relacionados con el mar, además creemos que es innovadora la decoración en sí del restaurante, recreando una lonja" (E.2.)

"Ofrecemos siempre rutas en contacto con la naturaleza promoviendo el senderismo y ecoturismo" (E.4)

"Buscamos iniciar un negocio familiar vinculado a prácticas responsables de disfrute de la naturaleza y del arte (...) fomentar un turismo respetuoso con el entorno natural (...) todos nuestros apartamentos son ecoeficientes" (E.6.)

"Como idea inicial es que en esa casa lo que queríamos era montar algo que le permitiese al cliente impregnarse del territorio: conocer nuestras costumbres, nuestra historia (...) además todos los productos gastronómicos que ofrecemos son KM0" (E.7)

Teniendo en cuenta que el aprovechamiento de las potencialidades propias del territorio junto con la adecuada utilización de los recursos endógenos constituye los elementos básicos de la estrategia que ha de impulsar la vitalidad económica y social del territorio (Rico y Gómez, 2009). Además, al procurar abastecerse únicamente de productos KM0 se genera un menor impacto en el cambio climático y, por supuesto, tiene una mayor repercusión en la creación de empleo local.

En este marco, la entrevistada E.10 añade que desde su empresa ya se están adelantando a la adaptación a las nuevas normativas que les puedan afectar, por ejemplo, en temas relacionados con el cambio climático. Por ejemplo, a través de un proyecto escolar impulsado en colaboración con la cofradía incrementan la visibilidad del sector pesquero, la concienciación ambiental y, de manera paralela, del papel de las mujeres.

En conclusión, se confirma que el turismo marinero no solo genera beneficios económicos de manera directa sino que también son significativos los beneficios económicos indirectos (Claesson, 2011; Pardellas y Padín, 2013). De hecho, se observa que las empre- 
sas analizadas en las zonas rurales costeras de Galicia demuestran haber contribuido a la modernización y sostenibilidad con proyectos innovadores que ayudan a incentivar la diversificación e impulso de proyectos que conllevan una mejora social para las comunidades marítimas.

\subsubsection{Puesta en valor de la cultura marítimo-pesquera}

Uno de los factores que más consenso suscita entre las empresarias entrevistadas es la aportación que suponen sus empresas a la puesta en valor los recursos patrimoniales (tanto materiales como inmateriales) del territorio:

"La vinculación familiar, emocional y cultural con el mar está muy presente en nuestro proyecto (...) como mujeres emprendedoras somos más sensibles con el tema de la sostenibilidad y la recuperación de lo tradicional (...) los platos que se ofrecen son recetas tradicionales que intentamos recuperar (...) mantener esa relación con la cultura de la zona y con el mar y trabajadores del mar, en emprendimiento es esencial este tipo de sensibilidad para potenciar la comunidad." (E.1.) "Estamos enfocados principalmente en escolares. Les enseñamos lo que es el mar. Los llevamos a la lonja para que lo conozcan y reconozcan el pescado. Luego lo cocinan ellos". (E.5.)

"Los pilares de nuestra filosofía son el mar, el arte y la poesía (...) las edificaciones fusionan la arquitectura moderna y tecnológica con la tradición marinera" (E.6.) "La idea era impulsar el turismo mariñeiro y de naturaleza vinculado con el mar, así como el patrimonio costero (...) hemos puesto en marcha actividades náuticas y de naturaleza que ofrecemos a nuestros clientes en colaboración con otras empresas. (E.9)

Aunque mayoritariamente dichos recursos están vinculados al mar, también se dan a conocer otros referentes culturales como, por ejemplo, de carácter literario, gastronómico, histórico, etc. El objetivo cultural no es un aspecto que se señale directamente en las fichas de los GALP pero es de destacar la referencia al valor cultural a través de los discursos de las entrevistas. Por ejemplo, algunas de las iniciativas destacables que se citan son la creación de salas de conferencias y bibliotecas en espacios compartidos en sus propios negocios (E.7) o la creación de páginas webs con contenido cultural (E.10). Todo ello con el objetivo de potenciar la dimensión social y cultural interactiva con sus públicos y promocionar la cultura marítima pesquera a través de diferentes elementos que identifican simbólicamente al territorio (Jiménez y García, 2018). Así mismo, el turismo se configura como la mejor forma de salvaguardar el patrimonio pesquero (Vallega, 2007; Jiménez y García (2018) y también a mudar el estigma que existió en un pasado acerca del mundo del mar (Nadel Klein, 2000).

Se puede concluir que, este modelo de emprendimiento femenino, además de tener carácter innovador, diversificado, participativo y responsable, se apoya en el patrimonio cultural y natural de las localidades pesqueras señalando la dimensión social y cultural como uno de los componentes más sobresaliente del turismo marinero. 


\subsection{Proyección social del emprendimiento femenino a través de la prensa}

Con la finalidad de conocer la información que ofrece la prensa en referencia al turismo marinero y, con especial hincapié, al papel que le otorga a las iniciativas de carácter femenino, a continuación, se exponen los resultados obtenidos.

La primera de las cuestiones analizadas se ha dirigido a conocer desde cuándo el turismo marinero ha comenzado a estar presente en las noticias que reflejan los medios de comunicación, de tal forma que permite también identificar el interés suscitado de esta tipología turística. La primera información que aparece publicada en prensa data del año $2007^{9}$ y hace referencia al hecho de que la Consellería de Pesca y Asuntos Marítimos propuso la creación de cuatro unidades específicas para la futura Ciudad del Mar, en ellas se abordan la evaluación de los recursos marinos, la lucha contra la contaminación en el mar, la acuicultura y la confección de estudios socioeconómicos. Al mencionar las actividades que se pretendían desarrollar, se destacaba, entre otras, el turismo marinero.

Se observa en la Figura 8 que el mayor porcentaje de noticias recogidas se han concentrado entre los años 2013 y 2019. El incremento a partir del 2013 viene dado por la creciente actividad de los GAC/GALP con iniciativas como "Come o Mar", "Ruta de los Faros"o el proyecto "Mar Galaica", entre otros.

El incremento más importante de noticias se produce a partir de principios de 2017 coincidiendo, tal y como se ha comentado anteriormente, con el hecho de que la mayoría de las empresas turísticas impulsadas por los GALP gallegos fueron creadas a partir de 2016 (un 97\%). Es preciso aclarar asimismo que, el hecho de que a 1 de junio de 2020 solo se hayan registrado 17 noticias tiene una explicación lógica contundente, y es que la crisis sanitaria de la COVID-19 y la aplicación, por parte del Gobierno español, del decreto del estado de alarma desde el 14 de marzo hasta el 21 de junio de 2020 para frenar la expansión de la pandemia, quedó parada toda productividad económica relacionada con el sector turístico.

Con relación a las publicaciones de noticias sobre el turismo marinero por Comunidades Autónomas, se pone de relieve que Galicia destaca y se manifiesta como un referente a nivel nacional acaparando el mayor número de informaciones (618 de un total de 1.217 a nivel nacional) e incluso, en algunos de los titulares, se proyecta como modelo de turismo marinero.

De las 618 noticias registradas, $90(14,56 \%)$ de ellas presentan la palabra clave "turismo marinero" también en el titular, además de en el cuerpo de la noticia. Las noticias donde se relacionan turismo marinero con los GAC/GALP, ya sea en el titular o en el cuerpo de la noticia, representan un 19,25\%, apareciendo la primera de ellas en octubre de 2009 y concentrándose la mayor parte a partir de finales de 2012, denotando una presencia más exponencial.

9 Se han detectado, a través de varias fuentes, noticias previas al 2007 pero la base de datos empleada, FACTIVA, no las aporta. 


\section{Figura 8 \\ NÚMERO DE NOTICIAS RECOGIDAS POR AÑO}

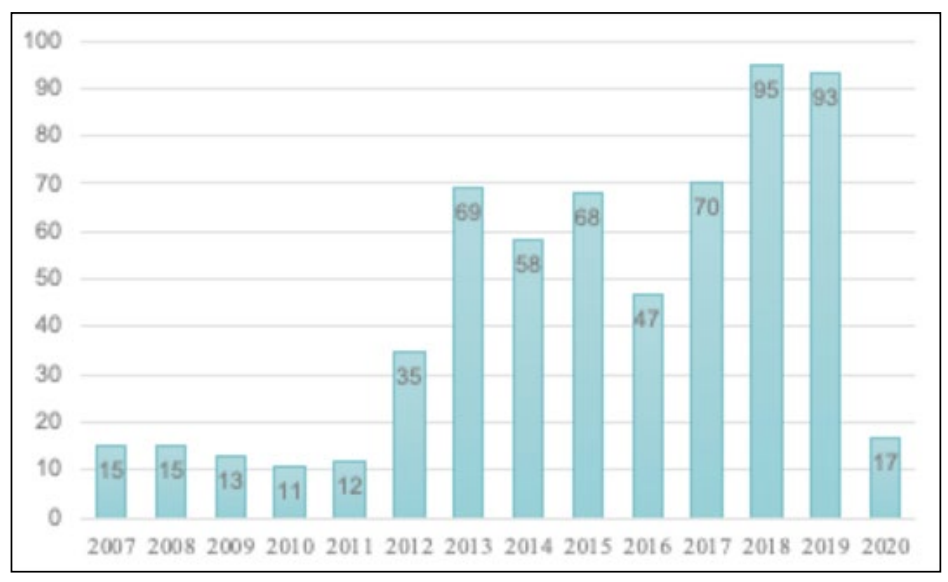

Fuente: Elaboración propia, basados en los datos registrados por FACTIVA

Nota: el corte de registro del año 2020 se realiza a 1 de junio.

También se ha observado que la mujer emprendedora de iniciativas en turismo marinero casi no aparece referenciada en las noticias, ya que solo un 8,42\% de estas noticias hacen mención directa a las mismas. Algunas de las agrupaciones, entidades o empresas citadas en las que se mencionan a las mujeres emprendedoras o de iniciativas relacionadas con el turismo marinero son: Agrupación Guimatur (compuesto por mariscadoras de las zonas de Carril, Vilagarcía de Arousa y Cambados), Agrupación de Marisqueo a Pie de Carril, Asociación Armarturmar (mariscadoras y pescadores de Cesantes), Apartamentos Hobbit de Galdo, Segittur (Sociedad Estatal para la Innovación y Tecnología Turística), Asociación de Mulleres do Mar de Cambados, Mariscadoras de Ribadeo, Mar Galaica, AmarCarril (mariscadoras de Carril), Candieira (Red de apoyo y promoción de mujeres del mar), Rederas de Cariño, Asociación de Mulleres do Mar de Poio, las Patronas de las Cofradías de O Pindo-Carnota e Ribadeo, Ruralover (Fundación Paideia), Ponle Cara al Turismo, Asociación Vilas Marineras y Pescanatura (estas dos últimas mencionan por igual a hombres y mujeres del sector).

En este sentido, se puede comprobar que la importancia del asociacionismo, relacionado con el turismo marinero y el emprendimiento femenino, se pone de evidencia a través de las agrupaciones o entidades que aparecen citadas en prensa, aún siendo todavía un colectivo minoritario, parece que se hace necesario como estrategia empresarial. La fotografía reflejo del mapa evolutivo general del turismo marinero en Galicia, y en particular la presencia social de la mujer emprendedora se puede comprobar a través de la siguiente Figura 9 donde se recogen algunos titulares destacados: 


\section{Figura 9 \\ RESUMEN TRATAMIENTO DEL TURISMO MARINERO EN GALICIA EN LA PRENSA ESCRITA}

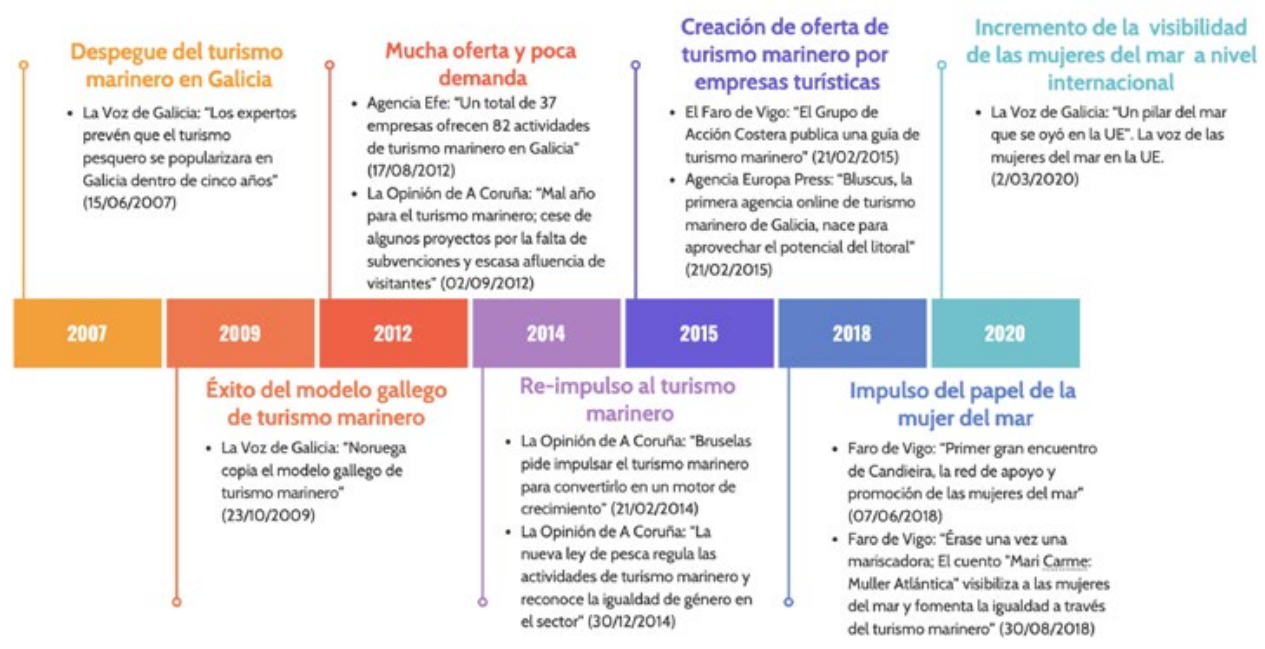

Fuente: Elaboración propia a partir de los datos extraídos de FACTIVA.

Se ha podido comprobar, a través de la revisión del contenido de estas noticias que, generalmente, se habla en sentido genérico sobre la empresa o la actividad pesquera, aludiendo apenas de forma directa, salvo en casos muy puntuales, a las mujeres emprendedoras. No obstante, a partir de 2018, la vinculación del turismo marinero y el rol femenino ha tenido mayor presencia en la prensa escrita, tal y como se puede comprobar en los titulares seleccionados de El Faro de Vigo de 2018 y La Voz de Galicia de 2020. Esta percepción va en línea con lo observado en la Figura 6 en el que 2019 se presenta con un mayor número de empresas con iniciativa femenina.

\section{CONCLUSIONES: ESCENARIO ACTUAL Y RETOS DE FUTURO}

El turismo marinero tiene posibilidades de convertirse en agente de cambio y en motor de desarrollo social y económico además de un instrumento de puesta en valor de los numerosos recursos de las comunidades rurales pesqueras (Patiño, 2016). No obstante, a pesar de que cada vez son más las iniciativas empresariales dedicadas al turismo marinero, no ha sido este un tema recurrente en la investigación académica a nivel nacional (MiretPastor et al., 2015; Herrera-Racionero et al., 2018). A través de este trabajo se ha obtenido un conocimiento más profundo desde la visión y percepción de las mujeres, como sujetos protagonistas centrales en este estudio, en su vinculación al turismo marinero y cuyos resultados permitirán tomar las acciones correspondientes en la planificación y gestión del turismo marinero sostenible. 
En cuanto a los hallazgos más relevantes y novedosos se destaca, en primer lugar, que una gran parte de los proyectos analizados se caracterizan por su carácter innovador, puesto que son proyectos originales que dan respuesta a las necesidades reales del territorio, tanto a nivel social, económico como cultural. Estas iniciativas de turismo marinero revelan así mismo unas definidas estrategias de diversificación que refuerzan y promueven el desarrollo local, puesto que suponen un complemento para la economía del lugar, siguiendo las necesidades establecidas por Farnet (2011). Además, el marcado nivel activo, participativo y responsable, con un claro afán de dinamización del territorio, muestran a una mujer emprendedora concienciada con el medio ambiente y el territorio. En resumen, los resultados confirman que el turismo marinero se presenta como una tipología turística sostenible (Ling y Chiao, 2017) y son proyectos cuyo consumo se apoya en el patrimonio cultural (material e inmaterial) y natural de las localidades litorales objeto de estudio.

En segundo lugar, cabe destacar también que la creación de empleo para las mujeres constituye uno de los objetivos reconocidos del desarrollo rural. En este sentido, es preciso poner también de manifiesto que, a través de estas iniciativas empresariales, se ha mejorado la visibilidad de las emprendedoras y ha aumentado asimismo la conciencia social sobre la importancia de su contribución al sector turístico, al tiempo que se han favorecido los procesos de empoderamiento y liderazgo femenino y se ha impulsado el asociacionismo, entre otros beneficios. Sin embargo, tal y como se ha corroborado a raíz del análisis de contenido en prensa, pese a los avances que se han producido en materia de igualdad y reconocimiento de estos derechos laborales de las mujeres, queda mucho trabajo por delante para conseguir una plena integración. Por ello, en el momento en el que se replanteen las nuevas estrategias de actuación de los GALP, habrá que seguir valorando los incentivos (económicos, de apoyo administrativo, de formación...) para el apoyo al emprendimiento femenino que debe de ser atraído, retenido y desarrollado.

En el caso gallego, hoy en día, no se puede afirmar que el turismo marinero sea una vía complementaria de ingresos para el sector pesquero dado que, mayoritariamente, las empresas implicadas son turísticas. No obstante, la labor que realizan de cara a la puesta en valor de la cultura marítima es indudable y con su labor están favoreciendo la conservación y promoción de la pesca y toda su cultura.

Aunque el turismo marinero es un producto diversificado, hay escépticos que argumentan que resulta aún insuficiente la demanda para poder llegar a ser rentable. Sin embargo, una vez presentados los resultados del estudio, parece coherente afirmar que el turismo marinero se visualiza con un potencial de mejora de su eficacia en un futuro cuasi presente, en un contexto post-covid 19, donde el turista se ve empujado a buscar actividades que ofrecen una experiencia más pausada (Fernández, 2020), sin masificaciones y más cercana al disfrute de lo original y auténtico (Vargas Sánchez, 2020), una autenticidad existencial, en línea al planteamiento de Wang (1999), con una visión más relacionada con la búsqueda simbólica del sentido del viaje y de la experiencia turística.

En definitiva, la tarea emprendedora llevada a cabo por estas profesionales ha permitido una revitalización y desarrollo en estas zonas rurales del litoral a través, tanto de la creación de riqueza y empleo como de la mejora de la conservación y puesta en valor de los recursos, a través de una diversificación turística innovadora como es el turismo marinero. Con ello, se puede confirmar también que en la costa gallega las empresarias están 
trabajando en línea con los ODS, lo cual confiere una gran importancia, dado que estos retos micro se podrían traducir en unos retos macro a nivel destino con mayor facilidad.

Este trabajo presenta una investigación preliminar que descubre ciertas limitaciones relacionadas, principalmente, con la escasa presencia femenina en el liderazgo de los proyectos turísticos de carácter marinero, así como con la falta de estadísticas sobre el número de turistas y su perfil. Además, si bien el papel de las mujeres como emprendedoras sociales está atrayendo cada vez más la atención (Datta y Gailey, 2012), existe asimismo una escasez de investigaciones sobre las mujeres emprendedoras sociales en el turismo. Por ello, a partir de los resultados de este estudio, se pueden plantear nuevas investigaciones que deriven en futuras propuestas encaminadas a fomentar la igualdad desde la perspectiva de género, así como la relación entre el emprendimiento y las características sociodemográficas.

\section{BIBLIOGRAFÍA}

ABRAHAMSSON, A. (2008): «Sustainopreneurship -business with a cause: the promise of creative business organizing for sustainability», en Johannisson y Lindholm Dahlstrand (Eds.), Bridging the functional and territorial views on regional entrepreneurship and development. Sweden, Swedish Foundation for Small Business Research, pp. 137-155.

ALARIO TRIGUEROS, M. y MORALES PRIETO, E. (2016): «Iniciativas de las mujeres: emprendimiento y oportunidades en el espacio rural de Castilla y León», Documents d'Anàlisi Geogràfica, vol. 62 (3), pp. 613-637.

ALEGRET, J.L. (2013): «Del patrimonio natural de los peces al patrimonio cultural del pescado: el espai del peix de palamos», Revista Andaluza de Antropología, $\mathrm{n}^{\circ}$ 4, pp. 33-54.

ATLAS.TI (8.1.3) (2020). Disponible en: https://atlasti.com/es/

BESTEIRO, B. (2004): «El desarrollo del turismo náutico en Galicia», Cuadernos de Turismo, $\mathrm{n}^{\circ} 13$, pp. 145-163.

BROULLÓN, ESMERALDA (2010): «Culturas marítimas y relaciones de poder. La trayectoria el marisqueo a pie en las Rías Bajas gallegas», Cuadernos de Estudios Gallegos, $\mathrm{n}^{\circ} 123$, pp. 375-399.

CENTRO TECNOLÓGICO DEL MAR (CETMAR) (2010): La pesca de bajura: situación en 2007 y perspectivas para una orientación sostenible. Recopilación de estudios realizados por el proyecto SEREA. Ed. CETMAR. Pontevedra.

CHEK SULAIMAN, F., JAINI, N., ROUZEE JAMALUDDIN, E. e IDZHAINEE HASHIM, N. (2018): «The impact of marine tourism towards the local community at Palau Pangkor, Perak». Asian Journal of Quality of Life, vol. 3 (13), pp. 168-176.

CHEN, C. (2010): «Diversifying fisheries into tourism in Taiwan: experiences and prospects», Ocean \& Coastal Management, vol. 53 (8), pp. 487-492.

DATTA, P.B. y GAILEY, R. (2012): «Empowering women through social entrepreneurship: Case study of a women's cooperative in India», Entrepreneurship Theory and Practice, vol. 36 (3), pp. 569-587.

FACTIVA (Bases de datos de prensa). Disponible en: http://www.factiva.com 
FARNET (2011): «Guía 5 Diversificación de las zonas de pesca». Disponible en: https:// www.mapa.gob.es/es/pesca/temas/diversificacion/analisisecononomicodeladiversifiacionpesquerayacuicola_tcm30-290383.pdf

FARNET (2013): «Uniendo la pesca con la economía del turismo». Disponible en: https:// webgate.ec.europa.eu/fpfis/cms/farnet/files/documents/FARNET_Magazine_09_ ES_0.pdf

FERNÁNDEZ HERNÁNDEZ, C. (2020): «Astroturismo rural: nuevas experiencias en tiempos pos-COVID», en Simancas, M., Hernández R. y Padrón, N. (Coords.) Turismo pos-COVID-19. Reflexiones, retos y oportunidades. La Laguna, Cátedra de Turismo CajaCanarias-Ashotel de la Universidad de La Laguna, pp. 535-543.

FUENTES GARCÍA, F.J. y SÁNCHEZ CAÑIZARES, S.M. (2010): «Análisis del perfil emprendedor: una perspectiva de género», Estudios de Economía Aplicada, vol. 28 (3), pp. 1-28.

GARCÍA NEGRO, M.C. y ZOTES, Y.N. (2006): «El trabajo de las mujeres en el sector pesquero gallego. Análisis de los problemas relacionados con su tratamiento estadístico». Revista Galega de Economía, vol. 15 (1), pp. 1-25

GESSA PERERA, A. y TOLEDANO (2011): «Turismo, emprendimiento y sostenibilidad en los espacios naturales protegidos. El caso de Andalucía (España)», Estudios y Perspectivas en Turismo, vol. 20 (5), pp. 1.154-1.174.

GRÀCIA, F. (2016): «El turisme pesquer», en Sánchez, J.LL. (Ed.) La pesca a la Mediterrània. Alicante, Universidad de Alicante, pp. 123-126.

HERRERA-RACIONERO, P., MIRET-PASTOR, L. y LIZCANO, E. (2018): «Viajar con la tradición: los pescadores artesanales ante la pesca-turismo en la Comunidad Valenciana (España)», Cuadernos de Turismo, n 41, pp. 279-293.

HOWARD, P. y PINDER, D., 2003: «Cultural heritage and sustainability in the coastal zone: experiences in south west England», Journal of Cultural Heritage, vol. 4 (1), pp. 57-68.

JIMÉNEZ DE MADARIAGA, C. y GARCÍA DEL HOYO, J.J. (2018): «Enhancing of the cultural fishing heritage and the development of tourism: A case study in Isla Cristina (Spain)», Ocean \& Coastal Management, vol. 168, pp. 1-11.

KHAKZAD, S. (2018): «Promoting coastal communities through cultural tourism: the case of fishing communities in Brunswick Country, North Carolina», Journal of Heritage Tourism, vol. 13 (5), pp. 455-471.

KHAKZAD, S. y GRIFFITH, D. (2016): «The role of fishing material culture in communities'sense of place as an added-value in management of coastal areas», Journal of Marine and Island Cultures, vol. 5 (2), pp. 95-117.

KIMBU, A.N. y NGOASONG, M.Z. (2016): «Women as vectors of social entrepreneurship», Annals of Tourism Research, vol. 60 (1), pp. 63-79.

LAVOZDEGALICIA(27/08/2018): «Turismomarinero, la otraindustria del marque ya suelta amarras». Disponible en: https://www.lavozdegalicia.es/noticia/mercados/2018/08/26/ turismo-marinero-industria-mar-suelta-amarras/0003_201808SM26P6992.htm.

Ley 33/2014 de 26 de diciembre por la que se modifica la Ley 3/2001 de 26 de marzo, de Pesca Marítima del Estado Español 
LING CHEN, C. y CHIAO CHANG, Y. (2017). «A transition beyond traditional fisheries: Taiwan's experience with developing fishing tourism», Marine Policy, vol. 79, pp. 84-91.

LORENZO, A. y MARTÍNEZ, M. (2003): «Condiciones y experiencias de participación en la Galicia rural», en Encina J. et al., (Coords.) Praxis participativa desde el medio rural. Madrid, Iepala Editorial-Cimas, pp. 301-320.

MARTÍNEZ GARCÍA, P. (2017): «Mirando al mar desde los feminismos. Comunidad y supervivencia en torno a las trabajadoras de la pesca». Prima social, 19, pp. 183-214.

MARTÍNEZ-GARCÍA, P. (2019). «Cuando las mujeres acceden al poder. discriminaciones y resistencias en las comunidades marineras», Feminismo/s, nº 33, pp. 171-196.

MARTÍNEZ, C. y MORENO, D. (2013): «La pesca como recurso turístico en Mazarrón (Murcia)». Estudios Turísticos, n 196, pp. 113-134.

MARTÍNEZ, C. y MORENO, D. (2014): Turismo marinero en Mazarrón: experiencia y futuro. Mazarrón, Ayuntamiento de Mazarrón.

MIRET-PASTOR, L., MOLINA-GARCÍA, A., GARCÍA-ARANDA, C. y HERRERARACIONERO, P. (2018): «Analysis of the fisheries diversification funds in Spain during the period 2007-2014», Marine Policy, vol. 93, pp. 150-158.

MIRET-PASTOR, L.; MUÑOZ ZAMORA, C., HERRERA-RACIONERO, P. y MARTÍNEZ NOVO, R. (2015): «Análisis regional del turismo pesquero en España», Revista de Análisis Turístico, vol. 20 (2), pp. 22-38.

MOLINA, A. GONZÁLEZ, J.F. y GARCÍA, C. (2010): «El turismo pesquero como instrumento de apoyo al desarrollo sostenible en zonas litorales: la experiencia del proyecto Sagital». Madrid, XIV International Congress on Project Engineering.

MORENO MUÑOZ, D. (2018a): La actividad pesquera en la Bahía de Mazarrón y el turismo marinero como propuesta de desarrollo. Tesis Doctoral. Universidad de Murcia.

MORENO MUÑOZ, D. (2018b): «Aportación a los conceptos de turismo marinero/pesquero y pesca-turismo", Cuadernos de Turismo, no 42, pp. 385-396.

MORENO MUÑOZ, D. y GARCÍA MARÍN, R. (2019): «El declive del sector pesquero en el Sureste de la Península Ibérica y el turismo marinero como propuesta de desarrollo», en Working Paper de la Red WATERLAT-GOBACIT dedicado a Pesca artesanal y patrimonio cultural: conflictos territoriales, resistencias y transformación social en Colombia, España y México, 6 (1), pp. 9-28.

MORENO MUÑOZ, D., GARCÍA MARÍN, R. y ESPEJO MARÍN, C. (2016): «Propuesta de turismo marinero en Mazarrón a raíz del Proyecto MARIMED. "La pesca como factor de desarrollo sostenible”», en Santos, X.M., Taboada, P. y López, L. (Eds.) Actas del X Congreso Internacional de Turismo Rural y Desarrollo Sostenible. Santiago de Compostela, Universidad de Santiago de Compostela, pp. 421-432.

MOVONO A. y DAHLES, H. (2017): «Female empowerment and tourism: a focus on businesses in a Fijian village». Asia Pacific Journal of Tourism Research, vol. 22 (6), pp. 681-692.

NADEL-KLEIN, J., (2000): «Granny baited the lines: perpetual crisis and the changing role of women in scottish fishing communities», Wom. Stud. Int. Forum, vol. 23 (3), pp. 363- 372 . 
ORGANIZACIÓN MUNDIAL DEL TURISMO (2011): Global report on women in tourism 2010. Madrid, World Tourism Organization.

OSUNA-RODRÍGUEZ, M., RODRÍGUEZ GARCÍA, L. y GÓMEZ PARRA, M. (2015): «Mujeres, Turismo Rural y Brecha Salarial de Género». Córdoba, Universidad de Córdoba.

PADÍN FABEIRO, C. y ABOY GARCÍA, S. (2010): «Nuevos productos turísticos: la apuesta por el turismo marinero en Galicia», Revista de Estudos Politécnicos, vol. 8 (14), pp. 55-83.

PADÍN, C., LIMA, C. y PARDELLAS, X.X. (2016): «A market analysis for improving fishing tourism management in Galicia (Spain)», Ocean and Coastal Management, vol. 130, pp. 172-178.

PARDELLAS, X. y PADÍN C. (2013): «Nueva demanda combinada de turismo litoral y turismo pesquero: motivaciones y efectos», Cuadernos de Turismo, $\mathrm{n}^{\circ} 32$, pp. 243-258.

PARDELLAS, X., PADÍN, C. y ABOY, S. (2011): «Turismo pesquero: experiencias en Europa y España», Papeles de Economía Española, nº 128, pp. 221-228.

PARDELLAS, X.X. y ESPEJO, C. (2013): «Turismo pesquero», en Solsona, X. y Pardellas, X.X. (Dirs.) La actividad turística española en 2012. Madrid, Editorial Universitaria Ramón Areces, pp. 433-440.

PATIÑO ROMARÍS, C.A. (2016): «El turismo marinero: un producto diferenciador y emergente de la oferta turística del litoral gallego», En Santos, X.M., Taboada, P. y López, L. (Eds.) Actas del X Congreso Internacional de Turismo Rural y Desarrollo Sostenible. Santiago de Compostela, Universidad de Santiago de Compostela, pp. 401-410.

PÉREZ CABRERA, A.M., TALLÓN FERNÁNDEZ, M.D., RODRÍGUEZ GUTIÉRREZ, P., y GUERRERO BAENA, M.D. (2017): «Estudio de la mujer emprendedora. El medio rural como oportunidad», RA \& DEM: Revista de Administración y Dirección de empresas, $\mathrm{n}^{\circ} 1$, pp. 1-12

PÉREZ PIERNAS, P. y ESPEJO MARÍN, C. (2012): «La pesca como factor de desarrollo del turismo sostenible. El caso de Águilas (Murcia)», Cuadernos de Turismo, $\mathrm{n}^{\circ} 30$, pp. 267-284.

PROYECTO SAGITAL (2017): «El papel de la mujer en el sector pesquero: potencialidades en el ámbito del turismo pesquero». Madrid, Fundación General de la Universidad Politécnica de Madrid. Disponible en: http://www.cesmuamfar.com/pdf/El_Papel_ de_la_Mujer_en_el_Sector_Pesquero._Potencialidades_en_el_\%C3\%A1 mbito_ tur\% $3 \%$ ADstico-pesquero.pdf

RED ESPAÑOLA DE MUJERES EN EL SECTOR PESQUERO (REMSP) (2017): La igualdad en cifras: Diagnóstico sobre la situación de la mujer en el sector pesquero y acuícola. Madrid, Ministerio de Agricultura y Pesca, Alimentación y Medio Ambiente. Disponible en: https://www.mapa.gob.es/es/pesca/temas/red-

RICO GONZÁLEZ, M. y GÓMEZ GARCÍA, M.J. (2009): «La participación empresarial de la mujer en las iniciativas de turismo rural en Castilla y León», Economía Agraria y Recursos Naturales, vol. 9 (2), pp. 51-77.

ROGELJA, N. y JANKO, A. (2017): «How authentic is fishing tourism in Slovenia?», en Rogelja, N. y Janko, A. (Eds.) Fish on the Move. Cham, Suiza, Springer International Publishing, pp. 145-170. 
SOLVOLL, G., ALSOS A. y BULANOVA, O. (2015): «Tourism entrepreneurship: review and future directions», Scandinavian Journal of Hospitality Tourism, vol. 15, $\mathrm{n}^{\circ}$ supl. 1, pp. 120-137.

VARGAS SÁNCHEZ, A. (2020): «Entender el turismo post-coronavirus: posibles escenarios», en Bauzá, F.J. y Melgosa, F.J. (Coords.) El turismo después de la pandemia global. Análisis, perspectivas y vías de recuperación. Asociación Española de Expertos Científicos en Turismo. pp 7-19

WANG, N. (1999): «Rethinking Authenticity in Tourism Experience», Annals of Tourism Research, vol. 26 (2), pp. 349-370. 
